\title{
Results of early curettage of giant congenital melanocytic nevi; a report of eight cases and review of the literature
}

\author{
Laura H. Zaal • Wolter J. Mooi • Henk J. Sillevis Smitt
}

Received: 19 September 2007 / Accepted: 15 November 2007 / Published online: 18 December 2007

(C) The Author(s) 2007

\begin{abstract}
The aim of this study was to investigate the longterm cosmetic and oncologic results following early curettage of giant congenital melanocytic nevi (GCMN). Neonates with GCMN treated with curettage within 4 weeks of age and with a minimum follow-up of 2 years were evaluated at the outpatient department. Scar formation was evaluated by means of the patient and observer scar assessment scale (POSAS). Biopsy specimens were analysed. In 9 years, eight neonates were treated. The mean follow-up period was 5.6 years. Six (75\%) patients developed re-pigmentation of the curetted skin, hypertrichosis returned in five cases. One patient developed hypertrophic scars, all others formed good scars. None of the patients developed a melanoma. Biopsy specimens showed nevus cells in the skin after curettage. In $50 \%$ of the patients curettage is followed by severe re-pigmentation. Since this treatment does not remove all nevus cells, long-term followup is essential to detect malignant transformation.
\end{abstract}

Keywords Giant congenital melanocytic nevi C Curettage · Cosmetic and oncologic results

\section{Introduction}

By definition, congenital melanocytic nevi (CMN) are present at birth, all others are acquired. Divisions into size groups are clinically relevant because the problems associated with $\mathrm{CMN}$ vary according to size [23]. The larger

L. H. Zaal $(\triangle) \cdot$ W. J. Mooi $\cdot$ H. J. S. Smitt

Plastic Surgery, Academic Medical Center,

Meibergdreef 9 ,

Amsterdam 1100 DD, The Netherlands

e-mail: zaal@nvpc.nl lesions are obviously more disfiguring and pose a greater threat to the psychological well-being of the patient. In addition, the risk of malignant transformation varies with size [23]. Therapeutic options depend on size and may pose major management problems. Ideally, the excision removes all nevus cells. Unfortunately, this is not always feasible due to the size and deep spread of Giant CMN (GCMN); in such instances, superficial ablative techniques such as laser therapy, dermabrasion, chemical peeling or curettage are indicated. The primary aim of curettage treatment is to improve of the cosmetic result; also, it is hoped that the reduction of numbers of nevus cells reduces the risk of malignant transformation.

The aim of this study was to investigate the long-term cosmetic and oncologic results of curettage of GCMN.

Operative technique

Johnson was the first to observe the phenomenon of a natural cleavage plane in newborns between the upper dermis, containing the majority of nevus cells and melanocytes, and the deeper dermis within the nevus [5]. He reported a case of a newborn with a CMN of the scalp being delivered with forceps. Part of the nevus was accidentally removed with the instrument and the resulting skin defect healed spontaneously. On this evidence, Johnson treated the remaining nevus with dermabrasion, and pigmentation did not return after a follow-up of 17 years. In 1987, Moss proposed a technique of curettage before 6 months of age but preferably as early as is feasible [13]. Curettage is said to become progressively more difficult to perform as the dermal component of the nevus becomes more coherent with increasing age.

Under general anaesthesia, curettage might be performed as a one-stage procedure in neonates. With a sharp curette, 
the nevus is scraped from its centre to the periphery of the nevus in the direction of maximum relaxation. The cleavage plane is easier to find when curettage is performed early in life, preferably within 2 weeks $[18,19]$.

\section{Materials and methods}

Over a 9-year period, starting in 1996, a subset of 93 patients with GCMN were treated at the department of Plastic, Reconstructive and Hand Surgery of the Academic Medical Centre of Amsterdam in The Netherlands. GCMN were defined as CMN larger than $1 \%$ in the face/neck region, and more than two percent elsewhere on the body [17].

Of these 93 patients with GCMN, covering 1 to $30 \%$ of the total body surface, ten patients were treated with curettage by the last author within 1 to 4 weeks after birth. Curettage was only indicated for GCMN located on the back, abdomen, trunk, thorax or extremities. These lesions could not be excised with primary wound closure after tissue expansion. All the patients were photographed preand postoperatively by a professional medical photographer.

For this study, we only included patients with a minimum follow-up period of 2 years, so our study population consisted of a total of eight patients. Distribution of location of GCMN over the body, age at treatment and sex are shown in Table 1. The newborns underwent one or two sessions of curettage, depending on the size of the lesion. We limited the curetted area to less then $15 \%$ of the total body surface at any one procedure to limit the blood loss. Pre- and postoperative haemoglobin $(\mathrm{Hb})$ concentration was determined in order to assess the possible need for blood transfusion. If mainly at the borders of the GCMN complete curettage could not be performed, the lesional periphery was further excised. Preoperative biopsies were taken for histopathologic evaluation after curettage. The patients were hospitalised for at least 1 week postoperatively, to optimize pain medication and wound care. Pain

Table 1 Distribution of age, sex and location of GCMN

\begin{tabular}{|c|c|c|c|c|}
\hline & Sex & Location GCMN & $\begin{array}{l}\text { Age } \\
\text { start }\end{array}$ & $\begin{array}{l}\text { Location } \\
\text { curettage }\end{array}$ \\
\hline 1 & $\mathrm{f}$ & $\begin{array}{l}\text { Thigh, abdomen, buttocks, } \\
\text { back }\end{array}$ & 4 weeks & Back, buttocks \\
\hline 2 & $\mathrm{~m}$ & Thigh, urogenital & 3 weeks & Thigh \\
\hline 3 & $\mathrm{f}$ & Thorax, back, legs & 2 weeks & Thorax \\
\hline 4 & $\mathrm{f}$ & Leg & 1 week & Leg \\
\hline 5 & $\mathrm{~m}$ & Buttocks, thigh & 2 weeks & Buttocks \\
\hline 6 & $\mathrm{f}$ & $\begin{array}{l}\text { Thigh, buttocks, } \\
\text { urogenital, leg }\end{array}$ & 4 weeks & Buttocks \\
\hline 7 & $\mathrm{~m}$ & Abdomen & 2 weeks & Abdomen \\
\hline 8 & $\mathrm{~m}$ & Urogenital, thigh & 1 week & Thigh \\
\hline
\end{tabular}

medication was given according to our hospital protocol and depended on the weight of the patient. The first few days the wound was covered with OpSite ${ }^{\circledR}$, after this silver sulfadine (Flammazine ${ }^{\circledR}$ ) crème was used until re-epithelialisation occurred. No systematic antibiotics were given.

The patients included for this study were invited once more to our outpatient department for clinical follow-up and especially for evaluation of all aspects of scar formation after curettage. For the latter, we obtained the validated patient observer and scar assessment scale (POSAS) [7].

Scar assessment

The POSAS consists of two scales: the observer scale and the patient scale. When the child was 8 years or younger, the parents filled out the scale. Both scales contain six items. The two observers rated scar (resulting from curettage) vascularity, pigmentation, thickness, relief, and surface area and pliability. The patient scale contains six questions applying to pain, itching, colour, pliability, thickness, and relief. Each of the six items on both scales has a 10-step score, with 10 indicating the worst imaginable scar or sensation. The total score of both scales consists of adding the scores of each of the six items, the range is from 6 (normal) to 60 (worse scar).

In addition, the observer and patient gave their overall opinion on the appearance of the scar, again a 10-step scale.

Because re-pigmentation was an important outcome in this study, we listed this item separately in Table 2.

\section{Results}

Seven out of the eight patients were seen in our out patient department. For geographic reasons, in one patient, the questionnaires were sent by mail, and the photographs were taken in another academic centre. Our mean follow-up period was 5.6 years (range 2.3 to 9.5 years). None of the patients needed blood transfusion after the curettage and the haemoglobin $(\mathrm{Hb})$ drop was minimal.

Table 2 shows the sum of the POSAS scores was almost completely made up by the item pigmentation. As seen in Table 2, these numbers vary between 15 and 24, which is a moderate scar. Due to the small number of patients, statistical analyses could not be performed. In addition, judgement of parents and observers was comparable. (Table 2). One patient developed hypertrophic scars due to infection, but all others formed good, pliable and soft scars after curettage. Two patients had mild re-pigmentation, two moderate and four patients had extensive repigmentation (Table 2). Re-pigmentation first appeared 2 months after curettage, with a mean of 3 months. Patients 
Table 2 Curettage outcomes

\begin{tabular}{lcllll}
\hline \multicolumn{2}{l}{ POSAS observer } & \multicolumn{2}{l}{ POSAS patient } & \multicolumn{2}{c}{ Re-pigmentation } \\
\hline 1. & 15 & 4 & 22 & 4 & 8 \\
2. & 19 & 5 & 19 & 5 & 8 \\
3. & 21 & 5 & 24 & 4 & 6 \\
4. & 15 & 3 & 20 & 4 & 3 \\
5. & 23 & 6 & 24 & 6 & 8 \\
6. & 12 & 3 & 11 & 3 & 2 \\
7. & 19 & 6 & 24 & 5 & 9 \\
8. & 14 & 5 & 16 & 5 & 5 \\
\hline
\end{tabular}

POSAS scores: the first number of the POSAS Observer and the first number of the POSAS Patient represents the total amount of adding the six separate items each with a 10-step score. For the observers these are vascularity, pigmentation, pliability, thickness, surface and relief. For the patients the six items are pain, itching, color, pliability, thickness and relief. The lowest total score is six and reflects with normal skin, whereas the highest score 60 reflects the worst imaginable scar. The second number of the POSAS Observer and Patient represent the overall opinion on the appearance of the scar. Again a 10-step scale was used in which 10 corresponded to the worst imaginable scar. The last item represents the re-pigmentation scores: $0-10 ; 1-4$ mild re-pigmentation, 5-7 moderate, 8-10 severe

in Figs. 1 and 2 show severe re-pigmentation. Hair growth returned in five cases. Histopathological biopsy specimen post curettage showed that intradermal pigmented nevus cells were present in all cases. None of our patients developed a malignant melanoma or non-melanomatous malignant tumor during follow-up.

\section{Discussion}

\section{Histology}

Essentially, CMN show the histological features of the far more common acquired nevi, the main difference being their larger size and the more extensive spread of nevus cells in the skin superficial dermis and along adnexae. Early studies have suggested that the congenital nevus does not yet involve the deep reticular dermal tissue at birth but that this develops during the first year of life [15, 21, 22]. Others noticed the importance of nevus size in determining the extent of dermal involvement already in the early postnatal period $[1,8,24]$.

Curettage of GCMN at a very early age has been based upon the supposedly superficial location of nevus cells and the finding of an easy cleavage plane between the upper and lower dermis during first weeks of life. Moss noted that this cleavage plane is not present in the normal skin and that it is not located at the junctional area of the nevus [13]. In 1973, Mark et al. mentioned that in the reticular dermis and subcutis, nevus cells in CMN are usually disposed as single cells between collagen bundles and fat cells, but also found nevus cells in the hair follicles which are surrounded by collagen sheaths with anchors in the subcutis, and in the erector pili muscles [9].

In our experience, the histological features of GCMN in infancy are variable, and may include the presence of large numbers of nevus cells arranged in densely cellular masses within the dermis. Such cellular masses, which contain little collagenous stroma, present a plausible explanation for the plane of cleavage found by the surgeon, since in contrast to normal collagen-rich reticular dermal tissue, such nevus cell masses provide little resistance to the physical trauma used by the surgeon. The plane of cleavage would thus lie in the level where cellularity of the nevus is high; this is in accordance with the finding of many nevus cells in the post-resection biopsies mentioned above. The disappearance of the "cleavage" plane after a few weeks of life can be explained by the gradual emergence of more collagenrich stroma within the main mass of the nevus.

Recently, the explanation for malignant transformation for GCMN has been sought in genetic mutations (BRAF
Fig. 1 a GCMN of a 4-weekold girl covering most part of the back and diaper region $(25 \%$ of the total body surface). Patient 1 in Tables 1 and 2.

b Results of curettage four months postoperatively performed at three weeks of age. Curettage at the borders was not possible. Only islands of pigmentations returned. c Results of curettage after a follow-up of 5 years. Note the severe repigmentation and hypertrichosis
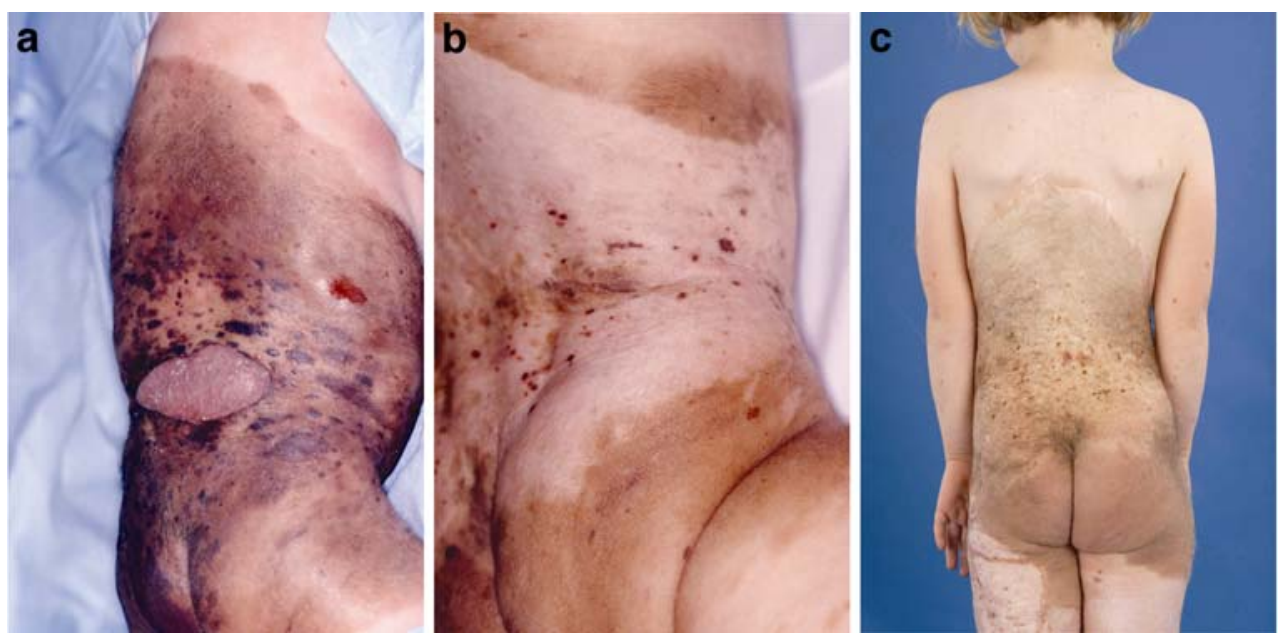
Fig. 2 a Results of curettage 3 weeks postoperatively performed at 1 week of age. No pigmentation has returned. Patient 2 in Tables 1 and 2. b Results of curettage 4 months postoperatively. Islands of pigmentations are visible. $\mathbf{c}$ Result of curettage 2 years postoperatively with severe re-pigmentation
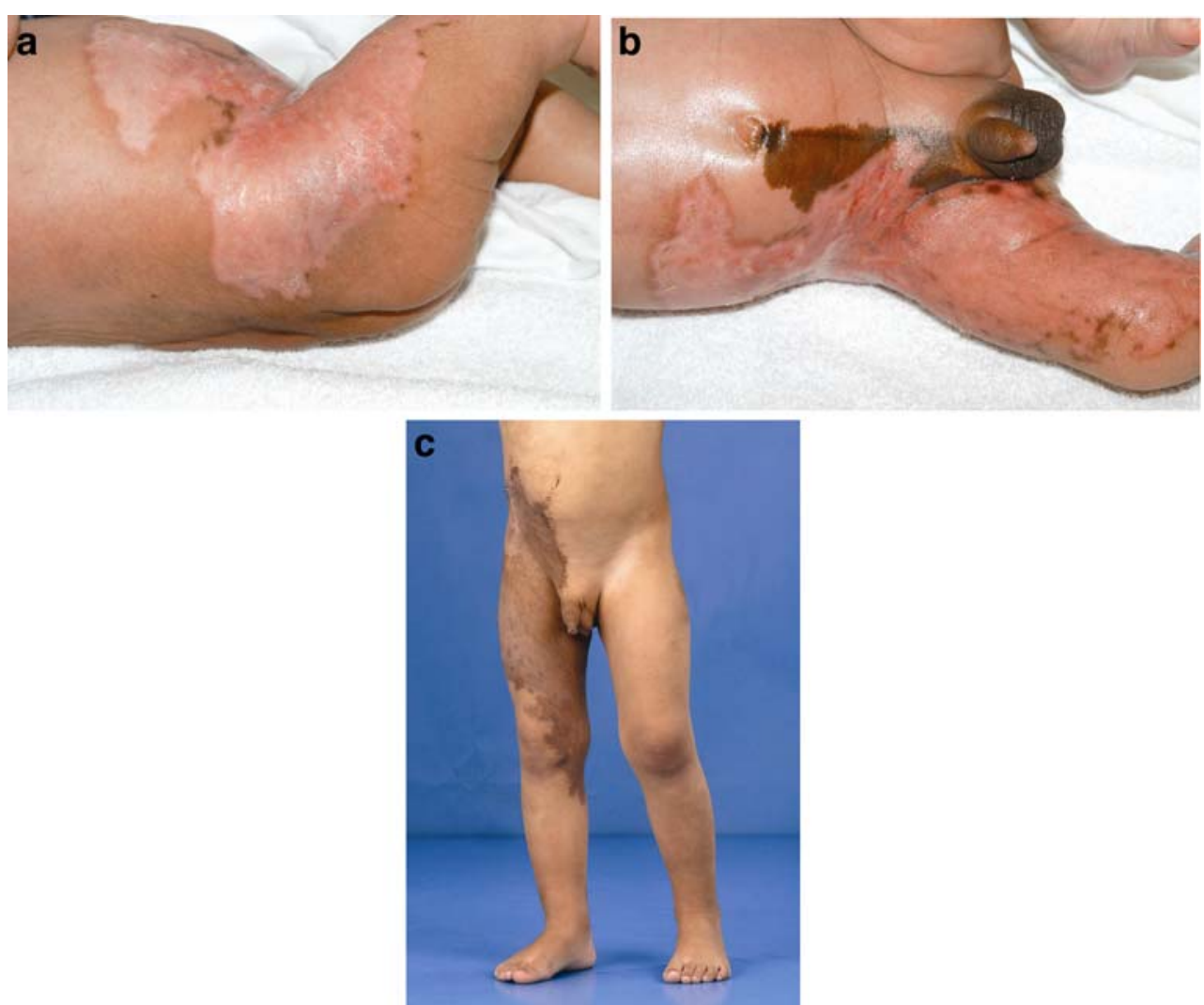

oncogene and NRAS mutations). Michaloglou showed in vitro and in vivo in our own CMN BRAF (V600E) expressing melanocytes [11] Nakato et al. detected $B R A F$ mutation in acquired nevi and small CMN [14]. Larger congenital nevi tend to harbour NRAS mutations rather than $B R A F$ mutations. Very recently De Raeve did not show oncogenic $B R A F$ mutation in curetted GCMN and excised MCMN, which could support her idea of removing the chance of malignancy with curettage [20]. There is no evidence that the risk of malignant transformation is different between small and medium-sized CMN, but GCMN are definitely associated with increased risk of developing melanoma [23]. This difference could, however, be accounted for by the fact that there are so many more nevus cells in a large congenital nevus.

De Raeve mentioned in her study that nevus cells in the superficial component of the GCMN, were more proliferative, and this component was more vascular compared with its deep component and with MCMN, which were not removed after curettage [20]. However, with curettage or indeed any trauma inducing a wound healing response, deeper nevus cells can be re-activated to proliferate. It is conceivable that such re-activated deep nevus cells which have recommenced proliferating can transform to malignancy, although the chance of this occurrence is probably unknown [3].
Treatment results

For the first time, our study used a validated scar scale to evaluate the results of treatment. In only one patient repigmentation almost did not occur, and four patients (50\%) developed severe re-pigmentation. Except for the patient

Table 3 Overview of the literature concerning curettage of GCMN

\begin{tabular}{|c|c|c|c|c|}
\hline Author & Patients & Location & $\begin{array}{l}\text { Age at } \\
\text { treatment }\end{array}$ & Results \\
\hline Moss & 10 & $\begin{array}{l}5 \text { bathing } \\
\text { trunk }\end{array}$ & $\begin{array}{l}2 \text { weeks- } \\
6 \text { months }\end{array}$ & $\begin{array}{l}3 \text { re- } \\
\text { pigmentation, } \\
6 \text { satisfactory }\end{array}$ \\
\hline de Mey & 6 & Unknown & Unknown & 5 satisfactory \\
\hline Kay & 1 & $\begin{array}{l}\text { Bathing } \\
\text { trunk }\end{array}$ & $<2$ weeks & Not satisfactory \\
\hline Casanova & 9 & $\begin{array}{l}\text { Back, } \\
\text { abdomen, } \\
\text { buttocks }\end{array}$ & $<7$ weeks & 6 satisfactory \\
\hline $\begin{array}{l}\text { De } \\
\text { Raeve }\end{array}$ & 19 & $\begin{array}{l}\text { Back, scalp, } \\
\text { arm, leg, } \\
\text { abdomen }\end{array}$ & $<2$ weeks & $\begin{array}{l}6 \text { moderate and } \\
3 \text { severe } \\
\text { repigmentation }\end{array}$ \\
\hline Zaal & 8 & $\begin{array}{l}\text { Back, } \\
\text { abdomen, } \\
\text { buttocks, } \\
\text { legs }\end{array}$ & $<4$ weeks & $\begin{array}{l}4 \text { severe re- } \\
\text { pigmentation }\end{array}$ \\
\hline
\end{tabular}


without re-pigmentation, all other patients underwent additional surgery because it was not possible to perform satisfactory complete curettage at the borders. All parents agreed that the postoperative period is very difficult and must not be underestimated, especially if the curettage area is in or near the diaper region.

The first treatment results of curettage were reported by Moss et al. in 1987 [13]. (Table 3). Moss stated that it is more difficult to find a cleavage plane at the age of 6 months and advised that curettage be performed before that age.

DeMey and colleagues reported satisfactory results in five out of six children [10]. In this study, the age of patients at treatment and the size and location of CMN are not specified. Kay published a case-report of an unsuccessful neonatal curettage of a classic "bathing trunk" GCMN within 2 weeks of life [6]. The procedure was stopped because there was no easy plane of cleavage. This is also in line with our experience, although if treated during first weeks of life, neonates with thick and hairy GCMN do not always have an easy and clear cleavage plane and curettage cannot be performed properly. In the literature and also in our study, the population the patients with elevated and hairy GCMN, showed hypertrichosis and re-pigmentation after curettage.

Casanova et al. reported data on nine neonates [2]. Treatment was deemed ineffective in three patients, in whom there was no cleavage plane. They mentioned that nevus cells persist in the deep dermal layers and may come to the surface, such that close monitoring is needed long after curettage.

De Raeve published in a period of 14 years a total amount of 19 neonates treated by curettage [18, 19, 20]. She is a strong supporter of curettage and advocates performing curettage during the first 2 weeks of life. In her last report, De Raeve presented data which support the idea that curettage of GCMN in neonates has the potential for lowering the risk of developing cutaneous melanoma by not only obtaining an important numerical reduction of nevus cells but also removing the 'active' melanocytes [20]. However, the surgical tissue trauma can to some extent reactivate nevus cells, which is macroscopically seen by the presence of re-pigmentation, and curettage is therefore best regarded first and foremost as a cosmetic treatment.

Apart from curettage, there are two other incomplete removal treatments of GCMN: dermabrasion, laser therapy and chemical peeling $[4,12,16]$. The disadvantage of dermabrasion is that it is followed by re-pigmentation if preformed (too) superficially, but it produces hypertrophic scares when performed too deeply. The same goes for laser treatment which has been justified on the basis of the superficial position of the majority of the pigment in GCMN. Again, the deeper nevus cells in the deep dermis and subcutaneous fat remain [6]. Furthermore, the nevus cells are repeatedly damaged by the laser treatment and thereby repeatedly inducing re-activation of the deeper located nevus cells. Among Dutch dermatologists, there is now consensus that pigmented lesions should not be treated with laser. Nowadays, even the group of Ostertag does not use the laser for treatment of GCMN anymore because of severe repigmentation [16].

Chemical peeling on the other hand can be an acceptable alternative treatment for lesions in the face.

In our opinion, any kind of incomplete treatment of congenital nevi is justified only when complete excision is impossible.

The reduction of the chance of malignant transformation is the key argument why surgical excision remains the standard of care.

In conclusion, in our series, early curettage resulted in $50 \%$ severe re-pigmentation in the long term. The disappearance of the "cleavage" plane after a few weeks can be explained by the gradual emergence of more collagen-rich stroma within the main mass of the nevus. The presence of re-pigmentation shows that it is unrealistic to aim at removal of all nevus cells with curettage. Long term follow-up and close monitoring of pigmentation remains essential to detect malignant transformation at an early stage.

Acknowledgment The authors like to thank dr. PPM van Zuijlen for providing the POSAS scale.

Open Access This article is distributed under the terms of the Creative Commons Attribution Noncommercial License which permits any noncommercial use, distribution, and reproduction in any medium, provided the original author(s) and source are credited.

\section{References}

1. Barnhill RL, Fleischli M (1995) Histologic features of congenital melanocytic nevi in infants 1 year of age or younger. J Am Acad Dermatol 33:780

2. Casanova D, Bardot J, Andrac- Meyer L et al (1998) Early curettage of giant congenital nevi in children. $\mathrm{Br} \mathrm{J}$ Dermatol 138:341

3. Hendrickson MR, Ross JC (1981) Neoplasms arising in congenital nevi. Am J Surg Pathol 5:109

4. Hopkins JD, Smith AW, Med M, Jackson IT (2000) Adjunctive treatment of congenital pigmented nevi with phenol chemical peeling. Plast Recon Surg 105:1

5. Johnson HA (1977) Permanent removal of pigmentation from giant hairy naevi by dermabrasion in early life. Br J Plast Surg 30:321

6. Kay AR, Kenealy J, Mercer NSG (1998) Successful treatment of a giant congenital melanocytic nevus with the thigh energy pulsed CO2 laser. Case-report. Br J Plast Surg 51:22 
7. van de Kar AL, Corion LU, Smeulders MJ et al (2005) Reliable and feasible evaluation of linear scars by the patient and observer scar assessment scale. Plast Reconstr Surg 116(2):514

8. Kuehnl-Petzoldt C, Kunze J, Mueller R et al (1984) Histology of congenital nevi during the first year of life. A study by conventional and electron microscopy. Am J Dermatopathol 6 (suppl):81

9. Mark GJ, Mihm MC, Liteplo MG, Reed RJ, Clark WH (1973) Congenital melanocytic nevi of the small and garment type. Human Pathol 4:395

10. De Mey A, Dupuis C, Lejeune F et al (1992) Neonatal treatment of giant nevi. Case-report. Dermatology 185:300

11. Michaloglou C, Vredeveld LC, Soengas MS et al (2005) BRAF 600 associated senescence like cell cycle arrest of human nevi. Nature 436:720

12. Miller CJ, Becker DW (1979) Removing pigmentation by dermabrading naevi in infancy. Br J Plast Surg 32:124

13. Moss AL (1987) Congenital giant naevus: a preliminary report of a new surgical approach. Br J Plast Surg 40:410

14. Nakato NI, Takata M, Takayanagi S et al (2006) High frequency of $B R A F^{\mathrm{V} 600 \mathrm{E}}$ mutation in acquired nevi and small congenital nevi, but low frequency of mutation in medium-sized congenital nevi. J Invest Dermatol 126:2111

15. Nickoloff BJ, Walton R, Pregerson-Rodan K et al (1986) Immunohistologic patterns of congenital nevocellular nevi. Arch Dermatol 122:1263
16. Ostertag JU, Quaedvlieg PJF, Kerckhoff SFE et al (2006) Congenital naevi treated with erbium YAG laser (Derma $-\mathrm{K}$ ) resurfacing in 10 neonates: clinical results and review of literature. Br J Dermatol 154:889

17. Pers M (1963) Naevus pigmentosus giganticus. Ugekr Laeger 125:613

18. De Raeve LE, De Coninck AL, Dierickx PR et al (1996) Neonatal curettage of giant congenital melanocytic nevi. Arch Dermatol $132: 20$

19. De Raeve LE, Roseeuw DI (2002) Curettage of giant congenital melanocytic nevi in neonates. A decade later. Arch Dermatol 138:943

20. De Raeve LE, Claes A, Ruiter DJ, van Muijen GNP, Roseeuw D, van Kempen LCLT (2006) Distinct phenotypic changes between the superficial and deep component of giant congenital melanocytic naevi: a rationale for curettage. Br J Dermatol 154:485

21. Silvers DN, Helwig EB (1981) Melanocytic nevi in neonates. J Am Acad Dermatol 4:166

22. Walton RG, Jacobs AH, Cox AJ (1976) Pigmented lesions in newborn infants. Br J Dermatol 95:389

23. Zaal LH, Mooi WJ, Sillevis Smitt JH, van der Horst CM (2004) Classification of congenital melanocytic naevi and malignant transformation: a review of the literature. Br J Plast Surg 57:707

24. Zitelli JA, Grant MG, Abell E et al (1984) Histologic patterns of congenital nevocytic nevi and implications for treatment. J Am Acad Dermatol 11:402 